\title{
Anti-inflammatory and anti-hyperuricemia properties of chicken feet cartilage: treatment on gouty arthritis animal model
}

\author{
Tri Dewanti Widyaningsih", Widya Dwi Rukmi Putri, Erni Sofia Murtini, Nia Rochmawati, Debora Nangin \\ Department of Agricultural Product Technology, Faculty of Agricultural Technology, Brawijaya University, Malang 65145, Indonesia.
}

\begin{tabular}{|c|c|}
\hline ARTICLE INFO & ABSTRACT \\
\hline $\begin{array}{l}\text { Article history: } \\
\text { Received on: } 22 / 03 / 2017 \\
\text { Accepted on: } 13 / 05 / 2017 \\
\text { Available online: } 30 / 07 / 2017\end{array}$ & $\begin{array}{l}\text { Gout is a form of inflammatory arthritis caused by the deposition of uric acid. The therapeutic approach to gout } \\
\text { is mainly divided by the treatment of inflammation and the management of serum urate level. This study aim to } \\
\text { investigate whether chondroitin sulfate (CS) and glucosamine in chicken feet cartilage powder (CFE) and } \\
\text { aqueous extract (AE) are able to decrease serum urate level and inflammation in animal model of gouty arthritis. }\end{array}$ \\
\hline $\begin{array}{l}\text { Key words: } \\
\text { Chicken feet cartilage, gout, } \\
\text { hyperuricemia, monosodium } \\
\text { urate, inflammation. }\end{array}$ & $\begin{array}{l}\text { liver XO inhibition were evaluated in vivo on oxonate-induced hyperuricemia rats. Anti-inflammatory property } \\
\text { was also determined on monosodium urate (MSU) crystal-induced paw edema model. CFE and AE } \\
\text { supplementation showed urate-lowering activity. However, both treatments were not able to inhibit in vitro and } \\
\text { in vivo XO activity. In MSU crystal-induced mice, the levels of paw swelling and lipid peroxidation were } \\
\text { increased; in addition, a decrease in the activities of SOD and changes in the expression of CD11b }{ }^{+} \text {TNF- } \alpha \text { and } \\
\text { CD } 11 b^{+} I L-6 \text { of the spleen were demonstrated. These changes were reverted to near normal levels upon CFE and } \\
\text { AE treatments. These results suggest that CS and glucosamine from CFE and AE show a potent therapeutic } \\
\text { effect against gouty arthritis. }\end{array}$ \\
\hline
\end{tabular}

\section{INTRODUCTION}

Gouty arthritis is a disease manifested as painful inflammation and occurs on the background of hyperuricemia or high plasma urate level (> $408 \mu \mathrm{mol} / \mathrm{L}$ ) (Choi et al., 2005; Fauci et al., 2008; Orlowsky et al., 2014). Hyperuricemia leads to urate crystal formation and deposition in the joints thus initiating inflammatory response by triggering proinflammatory mediator production, such as reactive oxygen species (ROS), tumor necrosis factor- $\alpha(\mathrm{TNF}-\alpha)$, and interleukin-6 (IL-6) (Ferrari et al., 2016; Inokuchi et al., 2008; Choi et al., 2005). Medication prescribed to treat gout includes urate lowering agents and nonsteroidal anti-inflammatory drugs (NSAIDs) but these agents are associated with intolerances or adverse effects (Busso and So, 2010; Khanna et al., 2012; Liu-Bryan and Lioté, 2005; Umamaheswari et al., 2009; Wang et al., 2008; Wortman et al., 2010). Thus, the development of novel natural agents with

\footnotetext{
* Corresponding Author

Tri Dewanti Widyaningsih, Department of Agricultural Product Technology, Faculty of Agricultural Technology, Brawijaya University, Malang 65145, Indonesia. Email: tridewantiw @ ub.ac.id
}

therapeutic potential against gout would provide great clinical significance.

Chondroitin sulfate (CS) and glucosamine are two compounds present abudantly in the joint cartilage (de los Reyes et al., 2000; Hoffman, 2001). The use of these compounds have become increasingly popular for treatment of arthritis as both are safe and have no adverse effect (Uebelhart et al., 2004; Lovu et al., 2008; Volpi, 2009; Nagaoka, 2014). In our previous research, CS and glucosamine had been succesfully extracted from chicken feet cartilage using aqueous method. Chicken feet cartilage were incubated in boiling water for 150 minutes yielding aqueous extract (AE) which contained $2.04 \pm 0.15 \% \mathrm{CS}$ and $8.12 \pm 0.95 \%$ glucosamine (Widyaningsih et al., 2016). Previous research showed that CS significantly inhibited IL-1 $\beta$ and TNF- $\alpha$ production from macrophages treated with MSU crystals (Orlowsky et al., 2014). CS also affects the solubility of urate in joint fluids (Choi et al., 2005). Nevertheless CS and glucosamine have never been tested in hyperuricemia. The aims of this study were to explore the anti hyperuricemic and anti-inflammatory properties of chicken feet cartilage aqueous powder (CFE) and extract (AE). 


\section{MATERIALS AND METHODS}

\section{Materials and reagents}

Chicken feet (broiler, 5-6 weeks old, $30 \pm 5 \mathrm{~g}$ ) were obtained from local market in Malang-Indonesia. All chemicals used were the highest analytic grade available obtained from Sigma-Aldrich (USA), Merck (USA), Megazyme (Ireland) and Nacalai (Japan).

\section{Chicken feet cartilage powder preparation (Jalal et al., 2012)}

Chicken feet were washed thoroughly and boiled for 10 min. Cartilage was separated manually, grounded, and dried at 65 ${ }^{\circ} \mathrm{C}$ for $24 \mathrm{~h}$. Dried cartilage was grounded again to obtained chicken feet powder (CFE).

\section{Chicken feet cartilage extract preparation (Shin et al., 2006)}

$10 \mathrm{~g}$ of CFE was extracted with $100 \mathrm{ml}$ of distilled water at $100{ }^{\circ} \mathrm{C}$ for $2.5 \mathrm{~h}$ and then centrifuged (5000 rpm, $\left.30 \mathrm{~min}\right)$. The supernatant was dried at $50{ }^{\circ} \mathrm{C}$ and then grounded yielding chicken feet cartilage aqueous extract (AE). The glucosamine and chondroitin sulfate content were determined using the standard procedure previously described (Tsai et al., 2012; Bitter and Muir, 1962).

\section{In vitro xanthine oxidase assay (Ferrari et al., 2016)}

CFE, AE and allopurinol (as positive control) were solubilized in DMSO (1\%) and distilled water in order to obtain concentrations $10 ; 20 ; 30 ; 40 ; 50$ and $100 \mu \mathrm{g} / \mathrm{mL} .500 \mu \mathrm{L}$ of each sample was added into $1.125 \mathrm{~mL}$ of phosphate buffer $(\mathrm{pH} 7.4)$ and $187.5 \mu \mathrm{L}$ of $\mathrm{XO}$ enzyme $(0.28 \mathrm{U} / \mathrm{mL})$. This solution was incubated for $10 \mathrm{~min}$ at $30{ }^{\circ} \mathrm{C}$. Then, reaction of enzyme began after adding $1.375 \mathrm{~mL}$ of xanthine substrate. The absorbances were obtained at $295 \mathrm{~nm}$ (Shimadzu) every minute for $10 \mathrm{~min}$. The results were calculated using formulation: (1-test inclination/blank inclination) $\mathrm{x} 100$ and expressed as percentage of XO inhibition.

\section{Experimental animals (rats and mice)}

Specific pathogen-free male BALB/c mice (25-30 g) and male wistar rats (150-180 g) were used in this experimental. The experimental procedures in this study were approved by Brawijaya Ethical Committee under registration number 563-KEP-UB and carried out in accordance with the Guide for the Care and Use of Laboratory Animals, published by the US National Institute of Health (NIH Publication, revised in 1985). All animals were purchased from Malang Murine Farm (Malang, Indonesia) and divided into experimental groups $(\mathrm{n}=5)$. Animals were housed in individual plastic cages with controlled environment. Water and standard chow were given ad libitum.

\section{Preparation of drugs and test solutions for in vivo methods}

Potassium oxonate suspension, $\mathrm{CFE}$ solution, $\mathrm{AE}$ solution and allopurinol solution were given based on body weight of each animal. CFE and $\mathrm{AE}$ were dissolved in distilled water and drugs (allopurinol and indomethacin) were solubilized in Na-CMC $0.8 \%$ (vehicle). Potassium oxonate and monosodium urate were suspended in sterile saline $0.9 \%$ before its use.

\section{Anti-hyperuricemic and inhibition of liver XOD activity (Ferrari et al., 2016)}

In order to evaluate the anti-hyperuricemic and inhibition of liver XOD activity of CFE and AE, animals were divided into five groups $(n=5)$ and injected with potassium oxonate to the animals of groups $2-5$ (300 mg/kg I.P.) on the first and third day of the experiment (Watanabe et al., 2006; Lima et al., 2015). Once a day, $1 \mathrm{~h}$ after the potassium oxonate injection, treatments were given by oral gavage. Non-hyperuricemia group (group 1) and hyperuricemia group (group 2) were administered with vehicle. Group 3 was treated with allopurinol (10mg/kg P.O.). Groups 4 and 5 were treated with CFE dose $208 \mathrm{mg} / \mathrm{kg}$ and AE dose 333 $\mathrm{mg} / \mathrm{kg}$. Those doses were chosen based on daily recommended intake of glucosamine $(1500 \mathrm{mg})$ and chondroitin sulfate (1200 $\mathrm{mg}$ ) in human (Hyde, 2005). On the third day, $1 \mathrm{~h}$ after treatments, rats were anesthetized with ketamine dose $100 \mathrm{mg} / \mathrm{kg}$ and xylasine dose $20 \mathrm{mg} / \mathrm{kg}$. Rats blood were obtained from abdominal aorta and centrifuged at $1500 \mathrm{~g}$ for $5 \mathrm{~min}$. Supernatant were collected and centrifuged at $3000 \mathrm{~g}$ for $10 \mathrm{~min}$ until complete sera separation. These materials were used for uric acid quantification. Rats livers were also collected and washed in cold saline solution $(0.9 \%)$ for XOD activity determination

\section{MSU crystal-induced inflammation in mice (Rasool and Varalakshmi, 2006)}

MSU crystal was prepared according to procedure previously described (Saegmiller et al., 1962). Inflammations were induced by MSU-crystal injection in subplantar region of the mouse right hind paw. All groups, except negative control group, received $0.1 \mathrm{ml}(40 \mathrm{mg} / \mathrm{ml})$ MSU crystal injection. CFE (30.04 $\mathrm{mg} / 20 \mathrm{~g}), \mathrm{AE}(48.09 \mathrm{mg} / 20 \mathrm{~g})$, and indomethacin $(0.39 \mathrm{mg} / 20 \mathrm{~g})$ were given orally by gavage $1 \mathrm{~h}$ prior to injection and repeated daily for the next 2 days. Edema formation was determined by measuring paw thickness at $0,4,24$, and $48 \mathrm{~h}$ after MSU crystal injection using a caliper rule. Mice were sacrificed at the end of study. Blood was collected from the inferior vena cava for MDA and SOD assay, while spleen was quickly removed and rinsed with cold saline for CD11 ${ }^{+}$TNF- $\alpha$ and $\mathrm{CD}^{-1} 1 \mathrm{~b}^{+} \mathrm{IL}-6$ assay using Flowcytometer.

\section{Statistical analysis}

The results are expressed as mean $\pm \mathrm{SD}$, and significant differences between the variables were analyzed using Minitab 16. Results were defined as statistically significant at $\mathrm{P}<0.05$.

\section{RESULTS}

\section{In vitro xanthine oxidase inhibitory activity}

Allopurinol, a xanthine oxidase inhibitor, was used as positive control and showed an inhibition of $89.75 \%(100 \mathrm{mg} / \mathrm{mL})$ and $\mathrm{IC}_{50}$ of $50.01 \mathrm{mg} / \mathrm{mL}$ However, as shown in Table 1, chicken feet cartilage powder (CFE) and aqueous extract (AE) did not show any inhibition against xanthine oxidase. 
Table 1: In vitro inhibitory xanthine oxidase activity of extract from chicken feet cartilage.

\begin{tabular}{cccc}
\hline Sample & $\begin{array}{c}\text { Concentration } \\
(\boldsymbol{\mu g} / \mathbf{m l})\end{array}$ & $\begin{array}{c}\text { Inhibition } \\
(\mathbf{\%})\end{array}$ & $\begin{array}{c}\mathbf{I C}_{\mathbf{5 0}} \\
(\boldsymbol{\mu g} / \mathbf{m l} \mathbf{\pm} \text { S.D) }\end{array}$ \\
\hline Allopurinol & 100 & 89.75 & $50.01 \pm 2.76$ \\
CFE & 100 & - & - \\
AE & 100 & - & - \\
\hline Chicken feet cartilage powder (CFE), aqueous extract & from chicken feet \\
cartilage (AE). Data present mean S.D (n=5).
\end{tabular}

\section{Effects of CFE and AE on serum urate levels in hyperuricemic rats}

Mean of serum urate levels in different experimental groups were illustrated in Figure 1. The intra-peritoneal injection of potasium oxonate solution was allowed significant increase $(\mathrm{P}<0.05)$ in serum urate levels in hyperuricemia group compared to normal control group. $\mathrm{CFE}$ and $\mathrm{AE}$ treatment were able to significantly reduce serum urate levels compared to hyperuricemia group. Allopurinol also promoted a significant $(\mathrm{P}<0.05)$ reduction on serum urate levels of hyperuricemic rats to value lower than in hyperuricemic animals.

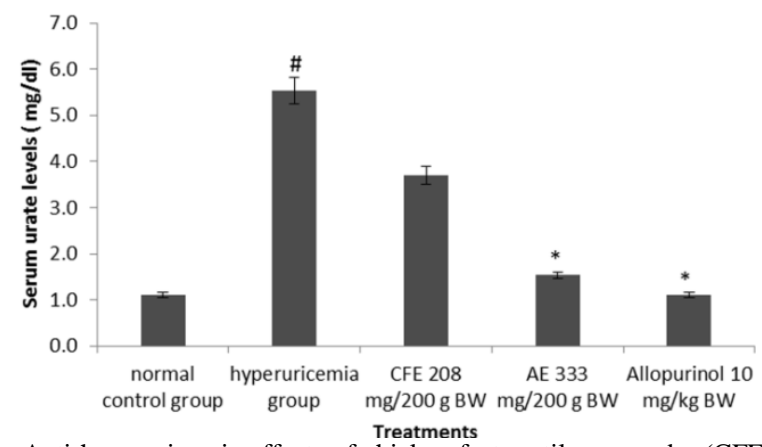

Fig. 1: Anti-hyperuricemic effects of chicken feet cartilage powder (CFE) and aqueous extract from chicken feet cartilage (AE) in rats pretreated with potassium oxonate. Experiments were performed as described in Materials and Methods. Data present mean S.D ( $n=5)$. One- way ANOVA followed by post hoc test (Least Significance Different) used for statistical significance. ${ }^{*} \mathrm{P}<0.05$ compared with hyperuricemic control group; $\# \mathrm{P}<0.05$ compared to normal control group

\section{Effects of CFE and AE on xanthine oxidase activity in rat liver}

The inhibitory activity of CFE and AE against xanthine oxidase was shown in Table 2. There was no xanthine oxidase inhibition observed in hyperuricemia group, as xanthine oxidase do not inhibited by potassium oxonate. In addition, treatment with CFE and AE also did not significantly $(\mathrm{P}>0.05)$ inhibited liver xanthine oxidase activity whereas allopurinol inhibited XOD activity by $49.90 \%$.

Table 2: Effects of CFE and AE on xanthine oxidase activity in rat liver in vivo.

\begin{tabular}{cc}
\hline Treatments & XOD activity $(\mathbf{U} / \mathbf{m g}$ protein) \\
\hline Normal control group & $1.51 \pm 0.87$ \\
Hyperuricemia animals & $1.06 \pm 0.44$ \\
CFE & $1.25 \pm 0.51$ \\
AE & $0.61 \pm 0.41$ \\
Allopurinol & $0.33 \pm 0.19^{*}$ \\
\hline
\end{tabular}

Chicken feet cartilage powder (CFE), aqueous extract from chicken feet cartilage (AE). Data present mean S.D ( $n=5)$. One- way ANOVA followed by post hoc test (Least Significance Different) used for statistical significance. $* \mathrm{P}<0.05$ compared with normal control group

\section{Edema formation and inhibition in mice}

To established the MSU-crystal inflammation, time course of edema formation in mice was conducted. MSU-crystals induced acuted inflammation as compared with the control group. Edema began to develop at first $4 \mathrm{~h}$ and reach its peak in $24 \mathrm{~h}$ (Figure 2). On the other hand, both $\mathrm{CFE}$ and $\mathrm{AE}$ groups considerably showed reduction $(\mathrm{P}<0.05)$ in the inflammation. Inhibition in positive control was used as a comparison to determine inhibitory activity of AE and CFE treatment (Table 3). Inhibiton rate of edema was calculated as follows: \% edema inhibition $=\left(\mathrm{V}_{24}-\mathrm{V}_{48}\right) \times 100 / \mathrm{V}_{24}$, where V24 and V48 were paw thickness at $24 \mathrm{~h}$ and $48 \mathrm{~h}$, respectively. Based on the statistic analysis, AE performed a significant $(\mathrm{P}<0.05)$ reduction in inflammation while $\mathrm{CFE}$ performed a reduction but not statistically significant $(\mathrm{P}>0.05)$.

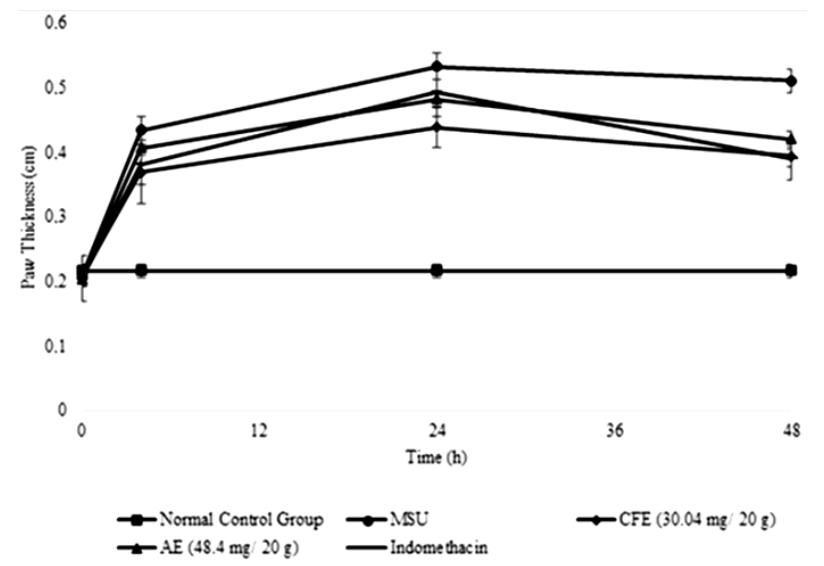

Fig. 2: Effects of chicken feet cartilage powder (CFE) and aqueous extract from chicken feet cartilage (AE) on paw edema in mice. Experiments were performed as described in Materials and Methods.

Table 3: Edema inhibition of CFE and AE on paw edema in mice.

\begin{tabular}{lc}
\hline Group & Edema Inhibition (\%) \\
\hline Normal Control Group & - \\
MSU & $4.13 \pm 0.75$ \\
CFE & $10.12 \pm 4.29$ \\
AE & $16.01 \pm 9.42^{*}$ \\
Indomethacin & $20.40 \pm 6.35^{*}$ \\
\hline
\end{tabular}

Chicken feet cartilage powder (CFE) and aqueous extract of chicken feet cartilage (AE). Values were expressed as mean \pm SD of 5 animals. One- way ANOVA followed by post hoc test (Least Significance Different) used for statistical significance. ${ }^{*} \mathrm{P}<0.05$ compared with MSU crystals injection groups.

\section{Lipid peroxidation and anti-oxidant status in mice}

MSU crystals injection triggered the oxidative stress in positive control group that was measureable in terms of increased MDA level and reduced SOD activity. Supplementation with AE and CFE had resulting in lower MDA level compared with positive control group although the difference was not significant $\mathrm{P}>0.05)$. In addition, $\mathrm{AE}$ and $\mathrm{CFE}$ administration showed a significant improvement $(\mathrm{P}<0.05)$ in SOD activity similar to that indometacin group when compared with positive control group. 
Table 4: MDA level and SOD activity in blood serum.

\begin{tabular}{lcc}
\hline Group & MDA level $(\mathbf{n g} / \mathbf{m l})$ & SOD activity $(\mathbf{U} / \mathbf{m l})$ \\
\hline Negative control group & $695 \pm 87.74$ & $3.34 \pm 0.34^{*}$ \\
MSU & $779 \pm 102.39$ & $2.26 \pm 0.67$ \\
CFE & $752 \pm 37.35$ & $2.84 \pm 0.48^{*}$ \\
AE & $727 \pm 93.10$ & $3.19 \pm 0.28^{*}$ \\
Indomethacin & $701 \pm 58.61$ & $3.22 \pm 0.60^{*}$ \\
\hline
\end{tabular}

Chicken feet cartilage powder (CFE) and aqueous extract of chicken feet cartilage (AE). Values were expressed as mean \pm SD $(n=5)$. One- way ANOVA followed by post hoc test (Least Significance Different) used for statistical significance. ${ }^{*} \mathrm{P}<0.05$ compared with MSU crystals injection group.

\section{Effects on pro-inflammatory cytokines in mice}

To examine the effect of $\mathrm{CFE}$ and $\mathrm{AE}$ on the production of inflammatory cytokines induced by MSU, TNF- $\alpha$ and IL-6 expression by macrophage were determined in spleen. As represented in Table 5, under basal condition, macrophages produced low pro-inflammatory cytokines $\left(\mathrm{CD} 11 \mathrm{~b}^{+} \mathrm{TNF}-\alpha\right.$ and $\left.\mathrm{CD} 11 \mathrm{~b}^{+} \mathrm{IL}-6\right)$ and MSU-crystal stimulation significantly increased the expression. However, CFE and AE were able to decreased proinflammatory cytokines expression in spleen $(\mathrm{P}<0.05)$ compared to the positive control group.

Table 5. Relative precentage of CD11b+TNF- $\alpha$ dan CD11b+IL-6

\begin{tabular}{lcc}
\hline Group & \% TNF- $\boldsymbol{\alpha}$ & \% IL-6 \\
\hline Negative control group & $8.96 \pm 2.72^{*}$ & $20.34 \pm 11.29^{*}$ \\
MSU & $24.32 \pm 9.17^{\#}$ & $43.82 \pm 9.75$ \\
CFE & $19.41 \pm 6.52^{\#}$ & $26.02 \pm 8.80^{*}$ \\
AE & $16.61 \pm 4.93$ & $25.29 \pm 4.33^{*}$ \\
Indomethacin & $22.33 \pm 8.66^{\#}$ & $20.99 \pm 6.36^{*}$ \\
\hline
\end{tabular}

Chicken feet cartilage powder (CFE) and aqueous extract of chicken feet cartilage (AE). Values were expressed as mean \pm SD of 5 animals. One- way ANOVA followed by post hoc test (Least Significance Different) used for statistical significance. $* \mathrm{P}<0.05$ compared with MSU crystals injection group; \#P $<0.05$ compared to negative control group.

\section{DISCUSSION}

Gout is a type of arthritis whose pathogenesis generally associated with hyperuricemia or high levels of uric acid $(>6.8$ $\mathrm{mg} / \mathrm{dL}$ ) (Fauci et al., 2008; Neogi, 2011). It usually comes with recurrent inflammation, intense pain, and red-swollen joint. As the prolonged use of synthetic chemical medicine associated with many side effects, a novel natural agent against gout was developed from glucosamine and CS. A number of studies have reported that glucosamine and CS possess anti arthritic action via various pathways (Chan et al., 2005). In our previous study, both glucosamine and CS had been succesfully extracted from chicken feet cartilage and possess anti-inflammatory effect against carrageenan-induced paw edema model in rats. In the present study, glucosamine and CS in the form of CFE and AE were used to treat animal model of gouty arthritis.

In the present study, treatment of $\mathrm{CFE}$ and $\mathrm{AE}$ were not capable to inhibit xanthine oxidase activity both in vitro and in vivo. Based on this result, it can be concluded that CS and glucosamine were able to lower serum urate level through the other mechanism. Administration of $\mathrm{CFE}$ on rats was not significantly reduced $(\mathrm{P}>0.05)$ serum urate levels due to the big molecular weight of CS polymer in CFE resulting in lower bioavailability compared to $\mathrm{AE}$ (Adebowale et al., 2000).
Reduction of serum urate levels in $\mathrm{AE}$ group may be due to the chondroitin sulphate and glucosamine are able to dissolve uric acid in rats. The solubility of uric acid may be due to chondroitin sulfate and glucosamine have the ability to draw water. Chondroitin sulfate and glucosamine are compound which contain negative charge in sulfate and carboxylic cluster, so that negative charge will attract water molecules because it contains positive ions $\mathrm{H}^{+}$(Prydz and Dallen, 2000). Furthermore, the more water bound up with chondroitin sulfate and glucosamine, fluid volume in rats will reduce to a decline in blood pressure. Falls in blood pressure activity in rats cause the activation of system renin angiotensin aldosterone system (RAAS). A mechanism of chondroitin sulphate and glucosamine in lowering the levels of uric acid different to the allopurinol mechanism. Allopurinol capable to inhibit the activity of xanthine oxidase through the mechanism acts as a compound similar to the substrate enzyme xanthine oxidase or purine binding site (Lima, 2015).

Besides hyperuricemia, inflammation also reported as a major problem that attacks gout patients. After MSU-crystal injection, paw thickness was significantly increased $(\mathrm{P}<0.05)$ compared to normal group. This increase in paw thickness probably caused by increase in vascular permeability resulting in edema formation. $\mathrm{CFE}$ and $\mathrm{AE}$ administration was able to inhibit the edema formation. Inhibition in edema formation was began to be seen at first 4 hour and remained in subsequent hours. This inhibition effect observed might be associated with anti inflammatory activity of glucosamine and CS present in CFE and AE (Du Souich et al., 2009).

In the patients with gout, there is a production of free radical caused by phagocytosis of MSU crystal. Production of free radical would ultimately lead to lipid peroxidation and impair antioxidant status (Murunikkara and Rasool, 2014). Those change can be measured as decreasing SOD activity and increasing in MDA level (Bottegoni et al., 2014). Administration of $\mathrm{AE}$ and CFE caused a reduction in MDA level and improvement in SOD activity. The mechanism seems to involve antioxidant properties of CS and glucosamine. The previous study had revealed that CS can act as antioxidant by increasing endogen antioxidant that can be measurable by SOD activity (Egea et al., 2010). Glucosamine supplementation also mediate anti-inflamatory effects by acting as antioxidant and decreasing nitric oxide synthase expresion and activity, and consequently the oxidative stess generated by ROS (Valvason, Musacchio, \& Pozzuoli, 2008). Our result demonstrated that CFE and AE also can reduced TNF- $\alpha$ and IL-6 expression in spleen. Indomethacin, a non-steroidal anti inflammatory drugs (NSAID) often prescribed for gout patients, also reduced $\mathrm{CD} 11 \mathrm{~b}^{+} \mathrm{TNF}-\alpha$ dan $\mathrm{CD} 11 \mathrm{~b}^{+} \mathrm{IL}-6$ level in spleen. Those cytokines were produced by various cells, including synovial cells, monocytes-macrophages, and neutrophils, and were well known to propagate a local or sistemic inflammatory response (Liu-Bryan and Lioté, 2005; Inokuchi et al., 2008; Schiltz et al., 2002). It can be stated that AE and CFE inhibits pro-

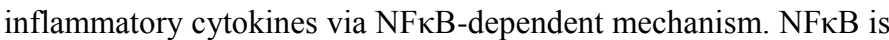
closely associated with pro-inflammatory cytokine production, 
such as IL-6 and TNF- $\alpha$. Since NFkB is a key player in inflammatory response, inhibition of it can be beneficial for modulating inflammatory diseases (Krishnan et al., 2014). The potent inhibiton of TNF- $\alpha$ and IL- 6 by glucosamine is due to inhibition of $\mathrm{NF} \kappa \mathrm{B}$ and production of $\mathrm{PGE}_{2}$. In addition, $\mathrm{CS}$ also acts on the nuclear translocation of NFKB (Bottegoni et al., 2014).

\section{CONCLUSION}

The present study demonstrated that glucosamine and CS from $\mathrm{AE}$ and $\mathrm{CFE}$ were remarkably able to ameliorate the gouty arthritis by decreasing serum urate level but not able to inhibit xanthine oxidase activity. In addition, the $\mathrm{AE}$ and CFE also possess anti-inflammatory activity through inhibition of proinflammatory mediator such as ROS, TNF- $\alpha$ and IL-6. Thus this study provides insights on possible utilization of CFE and $\mathrm{AE}$ as an anti-gouty arthritic-supplement. These evidences also gives information regarding their anti-hyperuricemic and antiinflammatory mechanism against gouty arthritic. However further investigations, will be necessary to investigate whether CFE and AE produces a similar therapeutic efficacy in human as was observed in this study.

\section{CONFLICT OF INTEREST}

The authors declare that there is no conflict of interests regarding the publication of this paper.

\section{AKNOWLEDGMENT}

Financial support and sponsorship: The author would like to thank Kemenristek (Ministry of Research, Technology and Higher Education of Republic Indonesia) and Brawijaya University which have funded this research through Leading Research University scheme 2015 and 2016.

Conflict of Interests: There are no conflicts of interest.

\section{REFERENCES}

Adebowale, A.O., Cox, D.S., Liang, Z., and Eddington, N. D. Chondroitin sulfate content in marketed products and the Caco-2 permeability of chondroitin sulfate raw materials. JANA, 2000; 3: 37-44.

Bitter, T., and Muir, H. M. A modified uronic acid carbazole reaction. Analytical Biochemistry, 1962; 4: 330-334.

Bottegoni, C., Muzzarelli, R. A. A., Giovannini, F., Busilacchi, A., Gigante, A. Oral chondroprotection with nutraceuticals made of chondroitin sulphate plus glucosamine sulphate in osteoarthritis. Carbohydrate Polymers, 2014; 109: 126-138.

Busso, N., and Alexander, S. Review: Mechanism of inflammation in gout. Arthritis Research \& Therapy, 2010; 12: 206-210.

Chan, P. S., Caron, J. P., Rosa, G. J. and Orth, M.W. Glucosamine and Chondroitin Sulfate Regulate Gene Expression and Synthesis of Nitric Oxide and Prostaglandin $\mathrm{E}_{2}$ in Articular Cartilage Explants. OsteoArthritis and Cartilage, 2005; 13: 387-394.

Choi, H. K., David, B. M., and Anthony, M. R. Pathogenesis of gout. Annals of Internal Medicine, 2005; 143: 499-516.

de los Reyes, G. C., Koda, R. T. and Lien, E. J. Glucosamine and chondroitin sulfates in the treatment of osteoarthritis. A survey. Prog.Drug Res. 2000; 55: 81-103.
Du Souich, P., García, A. G., Vergés, J. and Montell, E. Immunomodulatory and anti-inflammatory effects of chondroitin sulphate. J. Cell. Mol. Med. 13, 2009; 8: 1451-1463.

Egea, J., Garcia, A. G., Verges, J., Montell, E., and Lopez, M. G. Antioxidant, anti-inflammatory and neuroprotective actions of chondroitin sulfate and proteoglycans. J. Osteoarthritis and Cartilage, 2010; 18: 24-27.

Fauci, A. S., Braunwald, E., Kasper, D. L., Hauser, S. L., Longo, D. L., Jameson, J. L., and Loscalzo, J. 2008. Disorders of purine and pyrimidine metabolism. In: 17 th ed. Harrison's Principles of Internal Medicine .United States of America: McGraw-Hill Companies Chapter 353.

Ferrari, F. C., Lima, R. C. L., Filha, Z. S. F., Barros, C. H., Araújo, M. C. P. M., and Saúde-Guimarães, D. A. Effects of Pimenta pseudocaryophyllus extracts on gout: antiinflammatory activity and antihyperuricemic effect through xantine oxidase and uricosuric action. Journal of Ethnopharmacology, 2016; 180: 37-42.

Hyde, T. E. 2005. Safe use of glucosamine and chondroitin sulfate supplements. Available at: www.spinehealth.com/conditions/arthritis/safe-use-glucosamine-and-chondroitinsulfate-supplements. [Accessed 06 April 2017].

Hoffman, A.R. Treatmentwith Cosequin of bilateral cofofemoral osteoarthritis in a Great Dane. Compendium Oct, 2001;888893.

Inokuchi, T., Ka, T., Yamamoto, A., Moriwaki, Y., Takahashi, S., Tsutsumi, Z., Tamada, D., Yamamoto, T. Effects of ethanol on monosodium urate crystal-induced inflammation. Cytokine, 2008; 42: 198-204.

Jalal, A. F., Chinar, M. R. and Bnar, M. I. Optimization of chitin extraction from chicken feet. J.Anal Bioanal Techniques, 2012; 3: 15 .

Khanna, D., Fitzgerald, J. D., Khanna, P. P., Bae, S., Singh, M. K., Neogi, T., Pillinger, M. H., Merill, J., Lee, S., Prakash, S., Kaldas, M., Gogia, M., Perez-Ruiz, F., Taylor, W., Liote, F., Choi, H., Singh, J. A., Dalbeth, N., Kaplan, S., Niyyar, V., Jones, D., Yarows, S. A., Roessler, B., Kerr, G., King, C., Levy, G., Furst, D. E., Edwards, N. L., Mandell, B., Schumacher, H. R. American College of Rheumatology guidelines for management of gout. Part 1: systematic nonpharmacologic and pharmacologic therapeutic approaches to hyperuricemia. Arthritis Care Res (Hoboken), 2012; 64: 1431-1446.

Krishnan, K., Mathew, L. E., Vijayalakshmi, N. R., Helen, A. Anti-inflammatory potential of $\beta$-amyrin, a triterpenoid isolated from Costus igneus. Inflammopharmacol, 2014; 22: 373-385.

Lima, R. C. L., Fernanda, C. F., Maíra, R. S., Bruna, M. P., Carmen, A. p., Dênia, A. S. G. Effects of extracts of leaves from Sparattosperma leucanthum on hyperuricemia and gouty arthritis. Journal of Ethnopharmacology, 2015; 161: 194-199.

Liu-Bryan, R., and Lioté, F. Monosodium urate and calcium pyrophosphate dihydrate (CPPD) crystals, inflammation, and cellular signaling. Joint Bone Spine, 2005; 72: 295-302.

Lovu, M. M., Dumais, D. G., and du Souich, M. D. Antiinflammatory activity of chondroitin sulfate. Osteoarthritis and Cartilage, 2008; 16: 14-18.

Murunikkara, V. and Rasool, M. Trikatu. A herbal compound that suppresses a monosodium urate crystal-induced inflammation in rats, an experimental model for acute gouty arthritis. Cell Biochem Funct. 2014; 32: 106-114.

Nagaoka, I. Recent aspects of the chondroprotective and antiinflammatory actions of glucosamine, a functional food. Juntendo Medical Journal, 2014; 2: 1-8.

Nakano, T., Zeb, P., Lech, O., and Mirko, B. Extraction, isolation and analysis of chondroitin sulfate from broiler chicken biomass. Process Biochemistry, 2012; 47: 1909-1918.

National Institutes of Health. 1985. Guide for the Care and Use of Laboratory Animals Public Health Service. Bethesda, NIH: NIH Publication. 443-452
Neogi, T. Clinical practice. Gout. N. Engl. J. Med., 2011; 364: 
Orlowsky, E. W., Thomas, V. S., Eulàlia, M., Josep, V., and Virginia, B. K. Monosodium urate crystal induced macrophage inflammation is attenuated by chondroitin sulphate: pre-clinical. BMC Musculoskeletal Disorders, 2014; 15: 318-324.

Prydz, K., and Dalen, K. T. Synthesis and sorting of proteoglycans. J. Cell Sci., 2000; 113: 193-205.

Rasool, M. and Varalakshmi, P. Suppressive effect of Withania somnifera root powder on experimental gouty arthritis: An in vivo and in vitro study. Chemico-Biological Interactions, 2006; 164: 174-180.

Reginster, J.Y., Deroisy, R., Rovati, L.C., Lee, R.L., Lejeune, E., Bruyere, O. et al. Long term effects of glucosamine sulphate on osteoarthritis progression: a randomized, placebo controlled clinical trial. Lancet, 2001; 357: 251-256.

Schiltz C, Liote F, Prudhommeaux F, Meunier A, Champy R, Callebert $\mathrm{J}$, and Bardin T. Monosodium urate monohydrate crystalinduced inflammation in vivo: quantitative histomorphometric analysis of cellular events. Arthritis \& Rheumatism, 2002; 46: 1643-1650.

Seegmiller, J.E., Howell, R.R., Malawista, S.E. The inflammatory reaction to sodium urate. JAMA, 1962; 180: 469-475.

Shin, S. C., You, S. J., An, B. K. and Kang, C. W. Study on extraction of mucopolysaccharide-protein containing chondroitin sulfate from chicken keel cartilage. Asian-Aust. J. Anim. Sci, 2006; 19: 601-604.

Tsai, J. H., Maureen, S., Kathleen, O., Maggie, M., Chi, Antonina, I. F., and Kelle, H. M. Glucosamine inhibits decidualization of human endometrial stromal cells and decreases litter sizes in mice. Biology of Reproduction, 2013; 89: 1-10.

Uebelhart, D., Malaise, M., Marcolongo, R., DeVathaire, F., Piperno, M., Mailleux, E., Fioravanti, A., Matoso, L. and Vignon, E. Intermittent treatment of knee osteoarthritis with oral chondroitin sulfate: A one-year, randomized, double-blind, multicenter study versus placebo. Osteoarthritis and Cartilage, 2004; 12: 269-276.

Umamaheswari, M., Asokkumar, K., Sivashanmugam, A. T., Remyaraju, A., Subhadradevi, V., and Ravi, T. K. In vitro xanthine oxidase inhibitory activity of the fractions of Erythrina stricta Roxb. Journal of Ethnopharmacology, 2009; 124: 646-648.
Valvason, C., Musacchio, E., and Pozzuoli, A. Influence of glucosamine sulphate on oxidative stress in human osteoarthritic chondrocytes, effects on HO-1, p22Phox and iNOS expression. Rheumatology, 2008; 47: 31-35.

Volpi, N. Quality of different chondroitin sulfate preparations in relation to their therapeutic activity. Journal of Pharmacy and Pharmacology, 2009; 61: 1271-1280.

Wang, S. Y., Yang, C. W., Liao, J. W., Zhen, W.W., Chu F.H., and Chang, S.T. Essential oil from leaves of Cinnamomum osmophloeum acts as a xanthine oxidase inhibitor and reduces the serum uric acid levels in oxonate-induced mice. Phytomedicine, 2008; 15: 940-945.

Watanabe, S., Yumi, K., Kaoru, S. and Tetsuya, F. Effect of human placenta extract on potassium oxonate induced elevation of blood uric acid concentration. Journal of Health Science, 2006; 52 (6): 738-742.

Widyaningsih, T.D., Widya, D.R., Erni, S., Sudarma, D.W., Novita, W., Rika, E., Nia, R., and Debora, N. Extraction of glycosaminoglycans containing glucosamine and chondroitin sulfate from chicken claw cartilage. Research Journal of Life Science, 2016; 3 (3): 181189.

Wortmann, R., MacDonald, P., Hunt, B. J. and Jackson, R. Effect of prophylaxis on gout flares after the initiation of urate-lowering therapy: analysis of data from three phase III trials. Clin Ther, 2010; 32: 2386-2397.

\section{How to cite this article:}

Widyaningsih TD, Putri WD, Murtini ES, Rochmawati N, Nangin D. Anti-inflammatory and anti-hyperuricemia properties of chicken feet cartilage: treatment on gouty arthritis animal model. J App Pharm Sci, 2017; 7 (07): 202-207. 